\title{
Loop-mediated isothermal amplification assays for screening of bacterial integrons
}

\author{
Guangchao Yu ${ }^{1,2}$, Lei Chen ${ }^{3}$, Chii-wann Lin ${ }^{4}$, Bing Li ${ }^{2}$, Hemiao Cui ${ }^{2}$, Siyi Chen², Jian Miao², Huawei Bian ${ }^{*}$, \\ Dingqiang Chen ${ }^{6}$ and Yang Deng ${ }^{2^{*}}$
}

\begin{abstract}
Background: The occurrence and prevalence of integrons in clinical microorganisms and their role played in antimicrobial resistance have been well studied recently. As screening and detection of integrons are concerned, current diagnostic methodologies are restricted by significant drawbacks and novel methods are required for integrons detection.

Results: In this study, three loop-mediated isothermal amplification (LAMP) assays targeting on class 1,2 and 3 integrons were implemented and evaluated. Optimization of these detection assays were performed, including studing on the reaction temperature, volume, time, sensitivity and specificity (both primers and targets). Application of the established LAMP assays were further verified on a total of 1082 isolates (previously identified to be 397 integron-positive and 685 integron-negative strains). According to the results, the indispensability of each primer had been confirmed and the optimal reaction temperature, volume and time were found to be $65^{\circ} \mathrm{C}, 45 \mathrm{~min}$ and $25 \mu \mathrm{L}$, respectively. As application was concerned, 361, 28 and 8 isolates carrying int $/ 1$, int/2 and int/3 yielded positive amplicons, respectively. Other 685 integron-negative bacteria were negative for the integron-screening LAMP assays, totaling the detection rate and specificity to be $100 \%$.
\end{abstract}

Conclusions: The int/1-, int/2- and int/3-LAMP assays established in this study were demonstrated to be the valid and rapid detection methodologies for the screening of bacterial integrons.

Keywords: Loop-mediated isothermal amplification (LAMP), Integron screening, Bacterial integrons, Class 1 integron, Class 2 integron, Class 3 integron

\section{Background}

In the past decades, indiscriminate abuse of existing antibiotics leads to proliferation of antibiotic resistance in microorganisms and consequently results in an increasing number of clinical failures in bacterial mediated diseases [1-3]. Up to date, a number of resistance mechanisms are responsible for the emergence and prevalence of antimicrobial resistance, such as plasmids and transposons [4].

Recently, the occurrence and prevalence of integrons in clinical microorganisms and their role played in antimicrobial resistance have been well studied. As a novel resistance determinant, integron was firstly reported in

\footnotetext{
*Correspondence: zorain@126.com; fedengyang@scut.edu.cn

${ }^{5}$ The Third Affiliated Hospital of Sun Yat-sen University, Guangzhou 510630,

China

${ }^{2}$ College of Light Industry and Food Sciences, South China University of

Technology, 381 Wushan Road, Guangzhou 510640, China

Full list of author information is available at the end of the article
}

1989 [5], and its mechanism and mobility, such as the excision and integration for gene cassettes, had been further investigated [5-14]. A complete integron platform may comprise three basic genetic elements, the integrase gene (intI), recombination site attI and a promoter (Pc). Pc is functionally demonstrated for all integrons and the integrase gene encodes a tyrosine-recombinase family integrase which mediates recombination between two recombination sites, mostly the proximal primary attI site and a secondary target called an attC site. Through specific excision and integration, gene cassettes become part of integron and mediate various function for the hosts, with resistance cassettes mostly identified [15-17]. Integrons have been classified and divided into several classes based on the differences and divergence in the

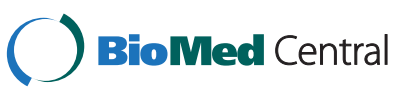

(C) 2014 Yu et al.; licensee BioMed Central Ltd. This is an Open Access article distributed under the terms of the Creative Commons Attribution License (http://creativecommons.org/licenses/by/4.0), which permits unrestricted use, distribution, and reproduction in any medium, provided the original work is properly credited. The Creative Commons Public Domain Dedication waiver (http://creativecommons.org/publicdomain/zero/1.0/) applies to the data made available in this article, unless otherwise stated. 


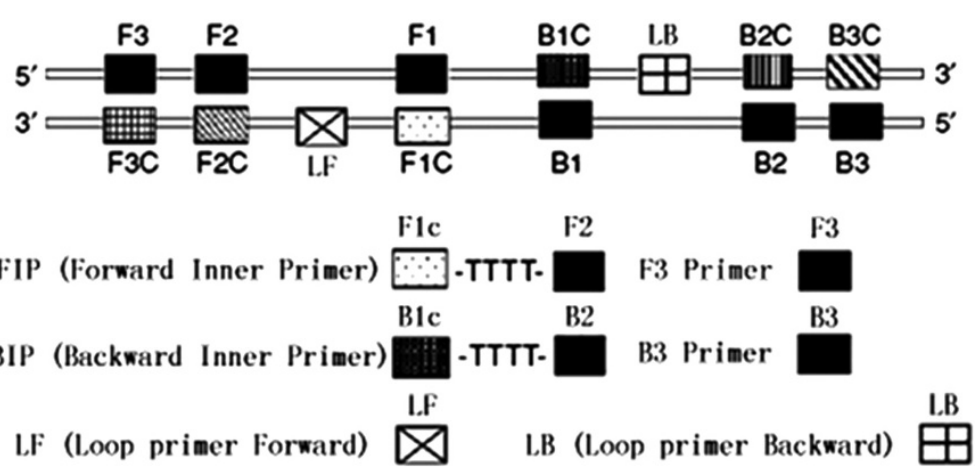

Figure 1 Schematic diagram of primers used in the LAMP assays. In detail, 6-8 distinct regions on every strand were used to design LAMP primers for the target gene. For the inner primers, the forward inner primer (FIP) consisted of the complementary sequence of F1 (F1C), a T-T-T-T linker and F2; the backward inner primer (BIP) consisted of the complementary sequence of B1 (B1C), a T-T-T-T linker and B2. The outer primers F3 and B3 located outside of the F2 and B2 regions, with loop primers LF and LB located beween F2 and F1 or B1 and B2, respectively. The scare bar is $10 \mathrm{~nm}$.

sequences of intI. Up to date, 4 general classes of integrons have been identified and distinguished, and classes 1 to 3 integrons are known as multi-resistant integron (RIs). RIs had been reported to be capable of acquiring same gene cassettes via similar recombination platform [18-22]. Currently, integrons are considered to be widely distributed and spread among clinical microorganisms and thus play a key role in the dissemination of such antimicrobial resistance, which may eventually contribute to the unleashing of "Super Bugs" [23-25].

As screening and detection of integrons were concerned, polymerase chain reaction (PCR) has been widely used.
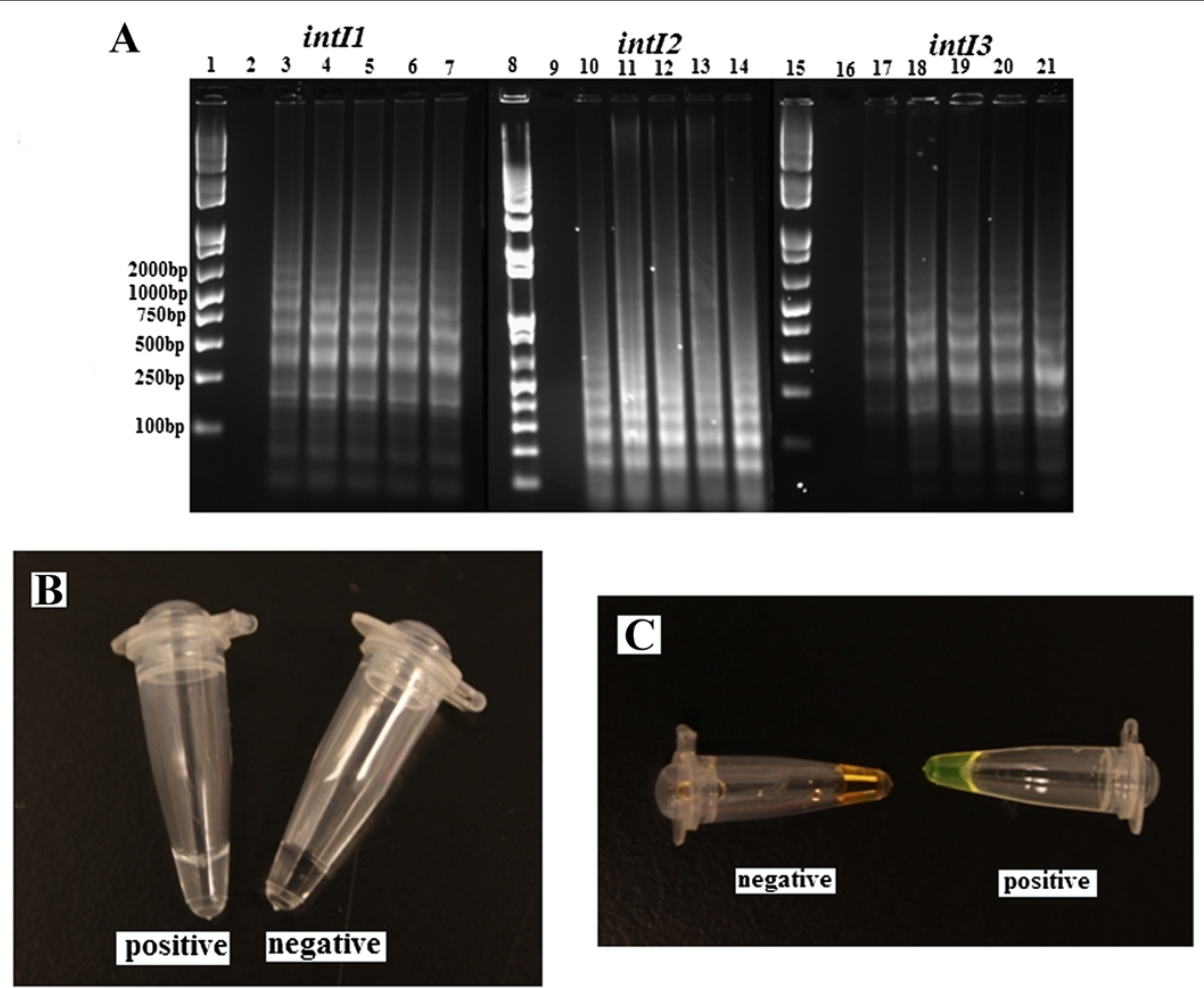

Figure 2 Determination of LAMP amplicons by gel electrophoresis, as well as observation directly by naked eye and under UV light in combination with Sybr Green stain. A: Monitoring of LAMP amplification by gel electrophoresis under different time points: lane 1-7, 8-14, 15-21 referring to LAMP assays of int11, int/2 and int13, respectively. Lane 1, 8, 15: DNA Marker; lane 2, 9, 16: 15 min; lane 3, 10, 17: 30 min; lane 4, 11, 18: 45 min; lane 5, 12, 19: 60 min; lane 6, 13, 20: 75 min; lane 7, 14, 21: 90 min. B: LAMP products were visually detected by the turbidity derived from the white precipitate of magnesium pyrophosphate. C: LAMP products dyed with Sybr Green I were visually detected by examining color changes with the naked eye. Assays were performed at $65^{\circ} \mathrm{C}$ for $45 \mathrm{~min}$. 
However, the requirement for PCR cycler machine and electrophoresis of PCR amplicons have restricted its further application, especially in clinical laboratory $[2,26]$. In the latest decade, loop-mediated isothermal amplification (LAMP), as a novel nucleic acid amplification method, had been reported [27-29] and applied to the detection of various pathogenic organisms [26,30-45]. This LAMP methodology relies on an auto-cycling strand displacement DNA synthesis performed by the Bst DNA polymerase large fragment, with 4 or 6 primers recognizing 6-8 distinct regions of the target gene (Figure 1) and generating the loop-mediated amplification under isothermal conditions between $60-65^{\circ} \mathrm{C}$ [27-29]. Amplicons are mixtures of many different sizes of stem-loop DNAs containing several inverted repeats of the target sequence and cauliflower-like structures with multiple loops $[30,46]$. In this study, LAMP assays on resistance integrons screening (including class 1, 2 and 3 integrons) were evaluated, optimized and further applied to the detection of a large scale of clinical isolates, with approximately $60 \mathrm{~min}$ required for the entire process.

\section{Results and discussion}

Optimization of integron-screening LAMP assays

Based on the amplification principle, the specific LAMP reaction generated many ladder-like pattern bands on agarose gel due to its characteristic secondary structure, with sizes ranging from $193 \mathrm{bp}$ for intI1, 148 bp for intI2 and $168 \mathrm{bp}$ for intI3, respectively (Figure 2). LAMP assays were performed under isothermal condition between $59^{\circ} \mathrm{C}$ and $66^{\circ} \mathrm{C}$ and none of significant difference was found. Sequences of the small-size amplicons were identical to those PCR amplified with F3 and B3. However, the LAMP product amplified at $65^{\circ} \mathrm{C}$ exhibited slightly larger amount of DNA amplicons when compared to other temperatures (data not shown), which was consistent with previous studies $[4,26,46]$. Reaction lengths of LAMP assays were varied between $15 \mathrm{~min}$, $30 \mathrm{~min}, 45 \mathrm{~min}, 60 \mathrm{~min}, 75 \mathrm{~min}$ and $90 \mathrm{~min}$, under $65^{\circ} \mathrm{C}$. With loop primers (LF and LB), the amplification was initially detected at $30 \mathrm{~min}$, and reached maximal detection levels at $45 \mathrm{~min}$. Nevertheless, without loop primers, amplification products were not detected until $90 \mathrm{~min}$ (data
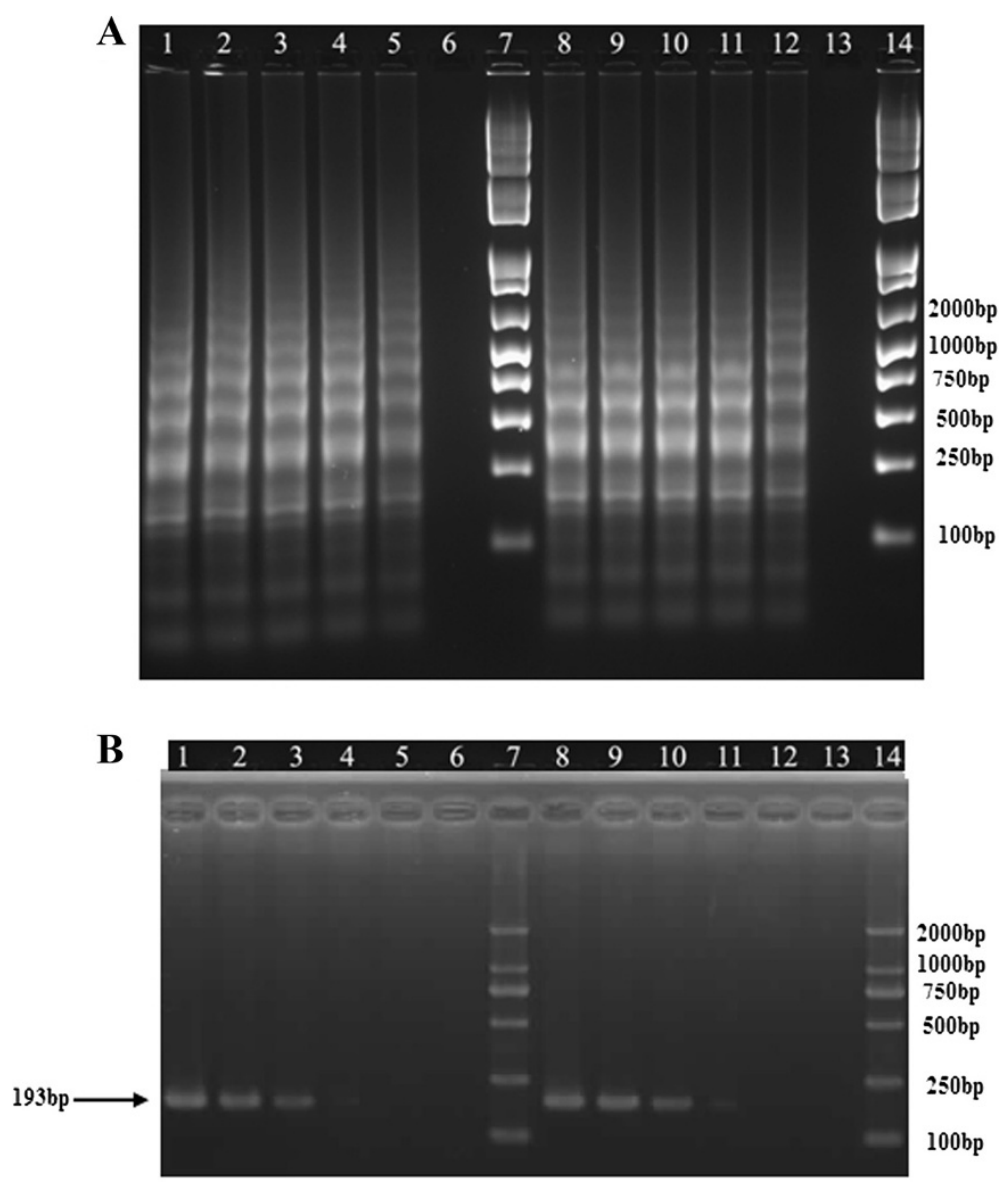

Figure 3 Sensitivity of LAMP (A) and PCR (B) assays for detection of class 1 integron (int/1). Lane: 1-6, 10 $5,10^{4}, 10^{3}, 10^{2}, 10,1$ CFU/reaction; 8-13: 1 ng, 100 pg, 10 pg, 1 pg, 100 fg, 10 fg DNAtube; Lane 7 \& 14: DNA Marker. LAMP assays were performed at $65^{\circ} \mathrm{C}$ for $45 \mathrm{~min}$. 
not shown). Primer specificity had been confirmed as no amplification was obtained in the absence of each of FIP, BIP, F3 or B3 primers, demonstrating LAMP assays were applicable only in the existence of both inner and outer primers. Therefore, each of the primers plays an indispensable role in auto-cycling strand displacement reaction by forming the loop out structure. All amplicons of integron-screening LAMP assays were determined by gel electrophoresis, as well as observation directly by naked eye and under UV light in combination with Sybr Green stain (Figure 2). The optimal reaction condition was determined as $65^{\circ} \mathrm{C}$ for $45 \mathrm{~min}$, and then used for further LAMP assays.

\section{Sensitivities of integron-screening LAMP and PCR assays}

The sensitivities of integron-screening LAMP and PCR assays were studied by the determination of both minimal CFU and minimal template DNA amount of bacteria. The detection limits of LAMP assays were found to be $100 \mathrm{fg}$ DNA/tube and $10 \mathrm{CFU} /$ reaction (LAMP was positive for sample containing $1 \times 10^{4} \mathrm{CFU} / \mathrm{mL}$, with $1 \mathrm{uL}$ was included in the reaction system) for intI1, while PCR was $10 \mathrm{pg} \mathrm{DNA} /$ tube and $10^{3} \mathrm{CFU} /$ reaction respectively, indicating that LAMP was 100 -fold more sensitive than PCR assays (Figure 3). The same results were also obtained in the other two integron-screening LAMP assays for intI2 and intI3 (Figures 4 and 5). Due to its powerful amplification efficiency, LAMP had been characterized by high sensitivity and low detection limits, showing a significant advantage compared with PCR assays in the present study. The established LAMP assays may acceptably fulfill the requirement of low level detection of bacterial integrons in the clinical specimens.

\section{Application of LAMP assays on a large scale of bacterial isolates}

After establishment and optimization, such integronscreening LAMP assays were applied to the detection of 1082 microorganisms, including 397 integron-positive and 685 integron-negative isolates, with comparative validation by standard PCR assays (Table 1). For application, rapid
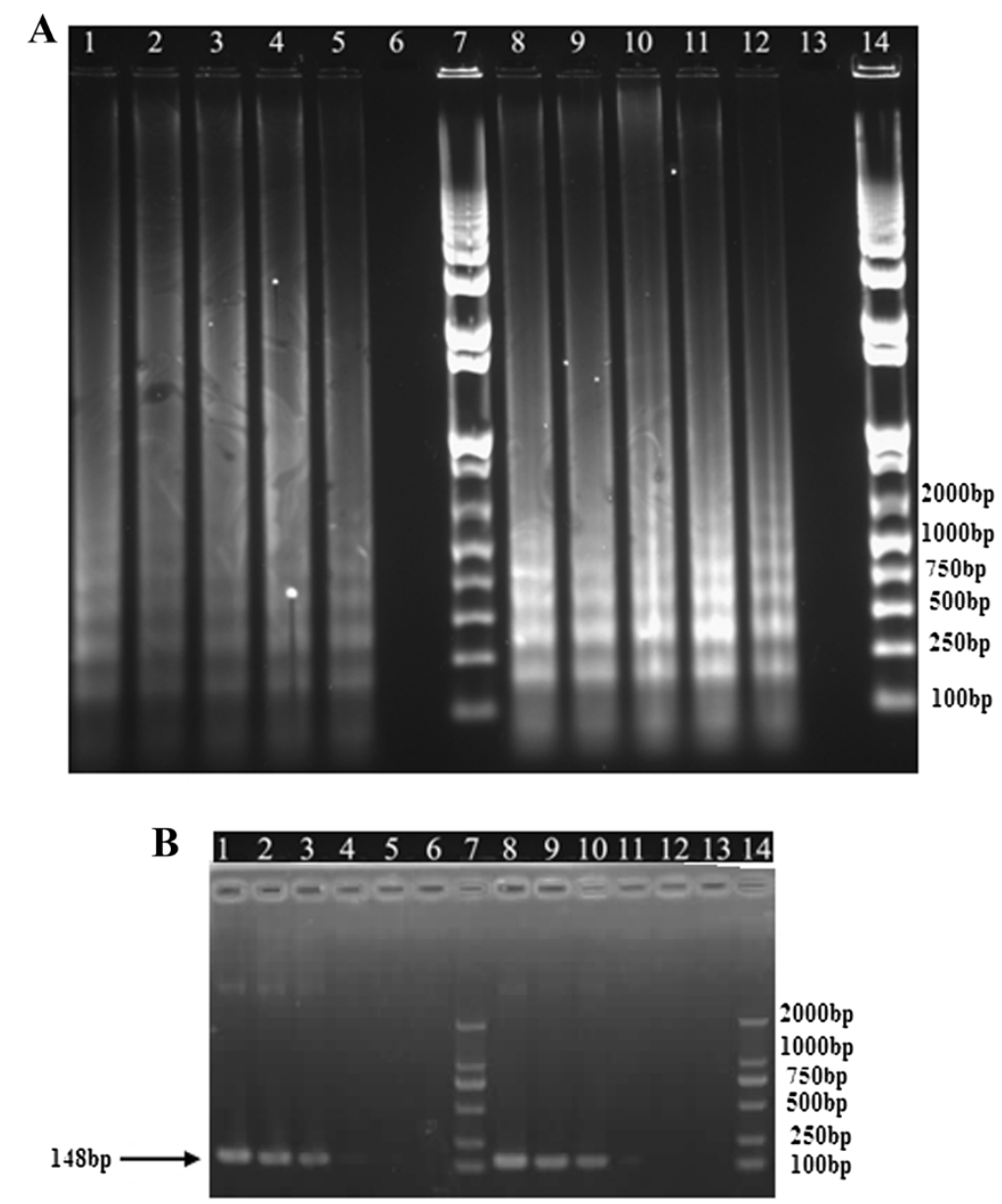

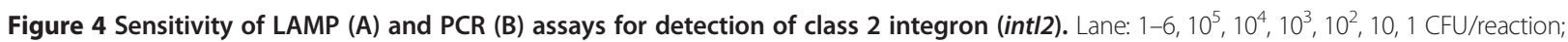
8-13: 1 ng, 100 pg, 10 pg, 1 pg, 100 fg, $10 \mathrm{fg}$ DNA/tube; Lane 7 \& 14: DNA Marker. These LAMP assays were performed at $65^{\circ} \mathrm{C}$ for $45 \mathrm{~min}$. 

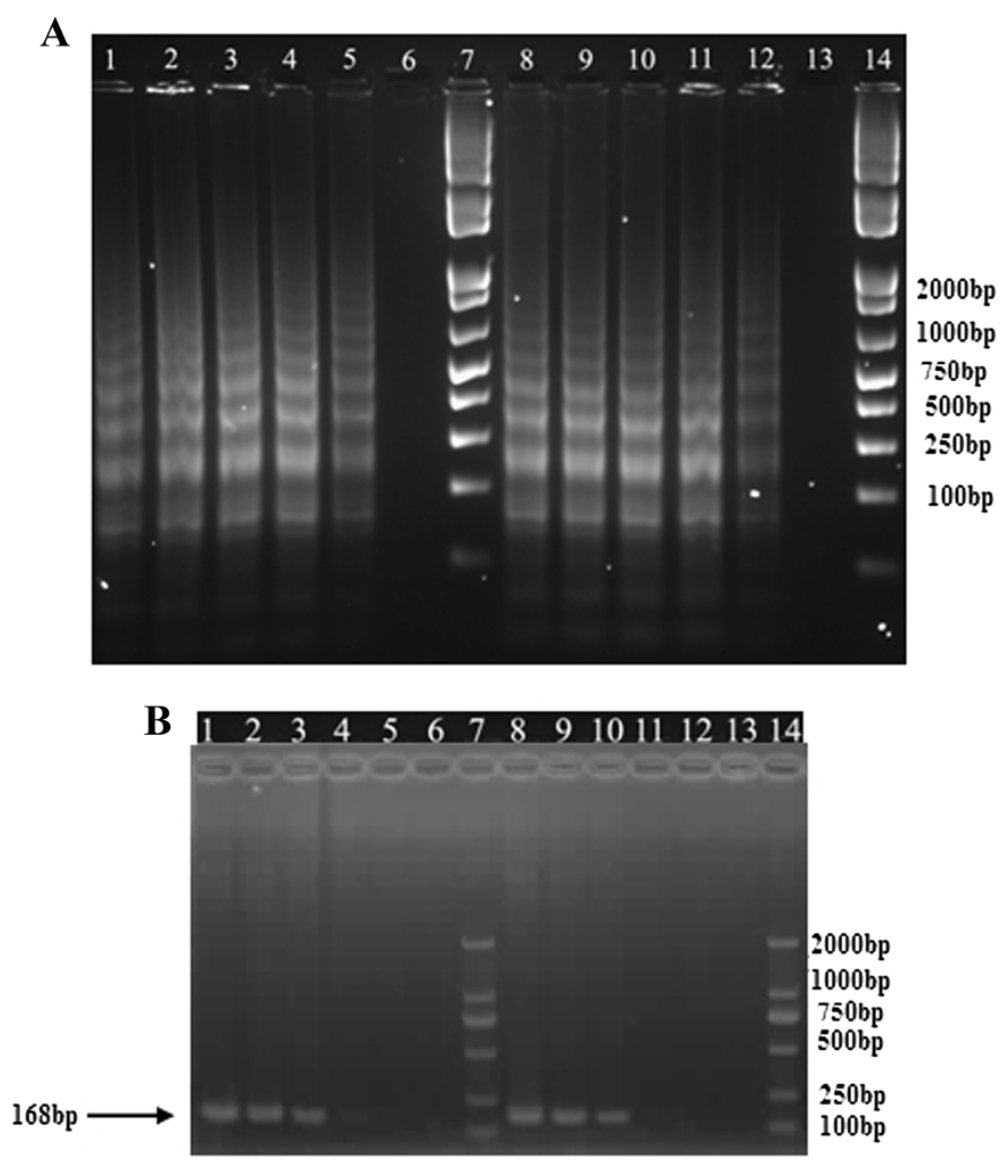

Figure 5 Sensitivity of LAMP (A) and PCR (B) assays for detection of class 3 integron (int/3). Lane: 1-6, 10 5 , 10 $10^{4}, 10^{3}, 10^{2}, 10,1$ CFU/reaction; 8-13: 1 ng, 100 pg, 10 pg, 1 pg, 100 fg, 10 fg DNA/tube; Lane 7 \& 14: DNA Marker. These LAMP assays were performed at $65^{\circ} \mathrm{C}$ for $45 \mathrm{~min}$.

DNA preparation process, simple heating equipments and results determination by observation directly by naked eye and under UV light had been applied. All of the 397 integron-positive isolates yielded positive amplicons and other 685 integron-negative bacteria were negative for the integron-screening LAMP and PCR assays, totaling 100\% detection rate (Table 1). All the reactions had been replicated, and high reproducibility (100\%) was obtained. For example, as shown in Figure 6, no difference was observed in the results of three parallel trials when the samples of Staphylococcus warneri 012502 (class 1 integron positive), Escherichia coli SK60 (class 2 integron positive) and Salmonella choleraesuis ATCC 1312 (three integrons negative) were detected in triplicates using integronscreening LAMP, respectively. Moreover, high specificity had been illustrated by no false positive observations for these reference strains during application in this study. With inner and outer primers recognizing six distinct regions, higher specificity should be achieved with LAMP as compared to more conventional PCR-based methodologies. Until recently, some other isothermal amplification techniques, such as nucleic acid sequence-based amplification and the self-sustained sequence reaction, were reported to be less specific due to their low reaction stringency $\left(40^{\circ} \mathrm{C}\right)$ [26]. Furthermore, these technologies require either a precision instrument for amplification or an elaborate method for detection of the amplified products, which restrict their broad application [26].

With the reaction performed under isothermal conditions without a thermal cycler, only simple equipment like a heat block and water baths were needed for the operation of LAMP assays at low expense. Additionally, the total detection time, including DNA preparation, LAMP reaction and results determination, was approximately 70 min, while conventional PCR methodology require nearly $2 \mathrm{~h}$ for amplification reactions alone. Therefore, the described LAMP methodology had been considered as the rapid, cost-effective, sensitive and specific detection assays for the screening of bacterial integrons.

\section{Conclusions}

In this study, 3 integron-screening LAMP assays targeting on intI1, intI2 and intI3 were developed and further applied to the rapid detection of the bacterial integrons 
Table 1 Reference strains included in the evaluation of integron-screening LAMP assays

\begin{tabular}{|c|c|c|c|c|}
\hline Reference strains & No. of isolates & $\ln t / 7^{\mathrm{a}}$ & $\ln t / 2$ & Int/3 \\
\hline Class 1 integron positive microorganisms & 361 & & & \\
\hline Escherichia coli & 109 & + & - & - \\
\hline Acinetobacter spp. & 21 & + & - & - \\
\hline Pseudomonas aeruginosa & 51 & + & - & - \\
\hline Klebsiella pneumoniae & 28 & + & - & - \\
\hline Enterobacter cloacae & 13 & + & - & - \\
\hline Staphylococcus aureus & 92 & + & - & - \\
\hline S. epidermidis & 16 & + & - & - \\
\hline S. haemolyticus & 5 & + & - & - \\
\hline S. hominis & 9 & + & - & - \\
\hline S. warneri & 1 & + & - & - \\
\hline Enteroccus faecalis & 9 & + & - & - \\
\hline E. faecium & 2 & + & - & - \\
\hline Stretococcus spp. & 5 & + & - & - \\
\hline Class 2 integron positive microorganisms & 28 & & & \\
\hline Pseudomonas aeruginosa & 20 & - & + & - \\
\hline Escherichia coli & 6 & - & + & - \\
\hline Proteus spp. & 2 & - & + & - \\
\hline Class 1 and 2 integrons positive microorganisms & 8 & & & \\
\hline Pseudomonas aeruginosa & 3 & + & + & - \\
\hline Enteroccus faecalis & 2 & + & + & - \\
\hline Escherichia coli & 3 & + & + & - \\
\hline Integrons negative microorganisms & 685 & & & \\
\hline Staphylococcus aureus & 138 & - & - & - \\
\hline S. epidermidis & 16 & - & - & - \\
\hline S. haemolyticus & 7 & - & - & - \\
\hline S. hominis & 8 & - & - & - \\
\hline S. capitis & 1 & - & - & - \\
\hline S. saprophiticus & 1 & - & - & - \\
\hline S. sciuri & 1 & - & - & - \\
\hline S. schleiferi & 1 & - & - & - \\
\hline S. intermedius & 1 & - & - & - \\
\hline Listeria monocytogenes & 58 & - & - & - \\
\hline L. invanovii & 2 & - & - & - \\
\hline L. welshimeri & 1 & - & - & - \\
\hline L. seeligeri & 1 & - & - & - \\
\hline Bacillus cereus & 6 & - & - & - \\
\hline Escherichia coli & 121 & - & - & - \\
\hline Vibrio parahaemolyticus & 108 & - & - & - \\
\hline V. vulnificus & 1 & - & - & - \\
\hline V. mimicus & 1 & - & - & - \\
\hline Pseudomonas aeruginosa & 153 & - & - & - \\
\hline Salmonella enterica & 44 & - & - & - \\
\hline
\end{tabular}




\begin{tabular}{cccc}
\hline S. typhimurium & 2 & - & - \\
S. choleraesuis & 1 & - & - \\
S. enteritidis & 2 & - & - \\
S. typhi & 3 & - & - \\
S. paratyphi & 1 & - & - \\
S. aberdeen & 1 & - & - \\
S. gallinarum & 1 & - & - \\
Klebsiella pneumoniae & 1 & - & - \\
Enterobacter cloacae & 1 & - & - \\
Yersinia enterocolitica & 2 & - \\
Total & 1082 & -
\end{tabular}

aAMP assays positive (+) and negative (-) results obtained in this study. Assays were performed in triplicates at $65^{\circ} \mathrm{C}$ for $45 \mathrm{~min}$.

of 1082 clinical strains. Both sensitivity and specificity were found to be $100 \%$. Comparing with conventional PCR, the intI1-, intI2- and intI3-LAMP assays exhibited advantages on detection limit, sensitivity, simplicity and rapidity. In conclusion, the described LAMP was demonstrated to be a valid and rapid detection method for integrons screening, which might aid in both the laboratory and clinical investigations.

\section{Methods}

\section{Bacterial strains}

For implementation and evaluation of the integronscreening LAMP assays, Vibrio cholerae O1 strain SK-10,
Escherichia coli strain WF108314 harboring an R483:: Tn7 plasmid and Serratia marcescens AK9373 were used as a positive control for class 1, 2 and 3 integrons, respectively. For application of the established LAMP assays, a total of 1082 strains were studied, including various species of gram-negative and gram-positive isolates (Table 1) with 397 integron-positive microorganisms and 685 integron-negative microorganisms, including 361, 28 and 8 isolates carrying intI1, intI2 and int I3, respectively. All these tested bacteria were provided by the First Affiliated Hospital of Jinan University (Guangzhou, China) and Zhongshan Supervision Testing Institute of Quality \& Metrology, and previously identified using standard

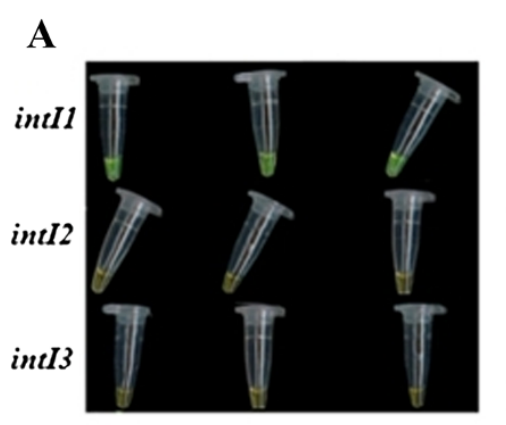

\section{B}
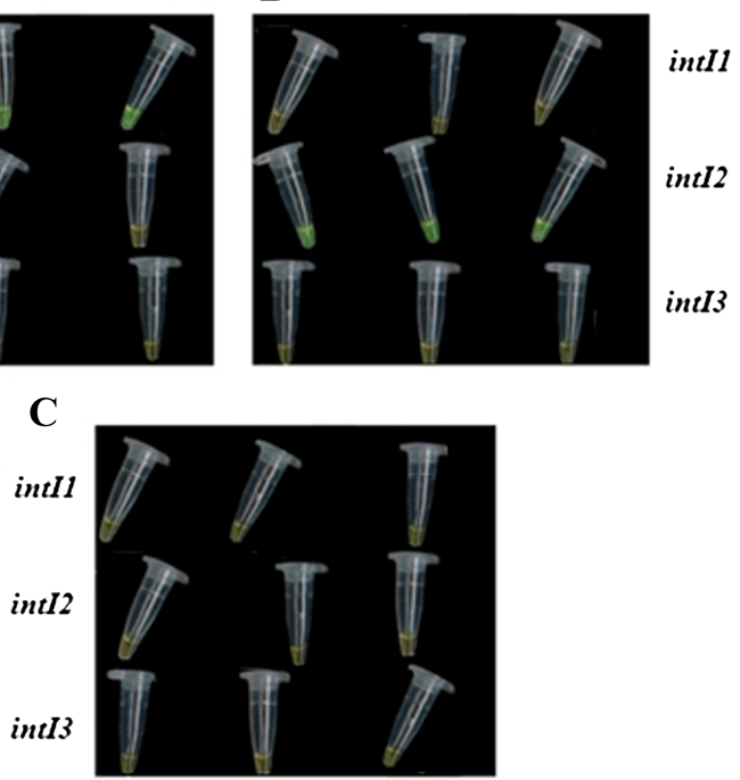

Figure 6 Results determination through observation at the color change by naked eye when integron-screening LAMP assays were employed to detect Staphylococcus warneri 012502 (A), Escherichia coli SK60 (B) and Salmonella choleraesuis ATCC 1312 (C) in triplicates. Green indicates a positive result and orange indicates a negative result. LAMP assays were performed at $65^{\circ} \mathrm{C}$ for $45 \mathrm{~min}$. 
procedures, including colony morphology, Gram staining, Vitek 2 automated system and the API ${ }^{\circ}$ commercial kit (BioMerieux, France) (unpublished data).

\section{Primer design}

For each of intI1, intI2 and intI3, a set of inner primers (forward and backward inner primers), outer primers (F3 and B3) and loop primers (LF and LB, to accelerate reaction) were specially designed for LAMP reaction to target 8 distinct regions (Figure 1 and Table 2). Forward inner primer (FIP)/backward inner primer (BIP) consisted of the complementary sequence of F1 (F1c)/B1 (B1c), a T-T-T-T linker and F2/B2; and outer primers F3 and B3 located outside of the F2 and $\mathrm{B} 2$ regions, respectively. Loop primers LF and LB were located between F2 and F1 or B1 and B2, which were designed to anneal at the loop structure of the amplicons and accelerate and enhance the sensitivity [27-29]. The primers were designed using PrimerExplorer V4 (PrimerExplorer, Eiken Chemical Co. Ltd.) according to the reference sequences of intI1, intI2 and intI3 acquired on GenBank (Nos. AF550415, AP002527 and AY219651).

\section{Preparation of template DNA}

Cultural conditions and template DNA extraction of the tested gram-positive and gram-negative strains were prepared as described previously [47-52]. In brief, these strains were innoculated Luria-Bertani (LB) broth and incubated overnight at $37^{\circ} \mathrm{C}$ with shaking. The collected culture was then diluted 10 -fold in $10 \mathrm{mM}$ Tris- $\mathrm{HCl}$ (pH 8.0) containing $1 \mathrm{mM}$ EDTA. The suspension was boiled for $10 \mathrm{~min}$ and further kept on ice. After centrifugation at 12,000 $\mathrm{g}$ for $3 \mathrm{~min}$, the resulting supernatant was used as templates for LAMP and PCR assays.

\section{Implementation, evaluation and optimization of integron-screening LAMP assays}

To implement and evaluate the integron-screening LAMP assays, $V$. cholerae O1 strain SK-10, E. coli strain WF108314 harboring an R483::Tn7 plasmid and S. marcescens AK9373 were employed as reference strains. Evaluation and optimization of this integron-screening LAMP included the investigation on mixture volume (3 volumes, with $12.5 \mu \mathrm{L}, 25 \mu \mathrm{L}$ and $50 \mu \mathrm{L}$ ), reaction temperature (8 temperatures, with $59^{\circ} \mathrm{C}, 60^{\circ} \mathrm{C}, 61^{\circ} \mathrm{C}, 62^{\circ} \mathrm{C}, 63^{\circ} \mathrm{C}, 64^{\circ} \mathrm{C}, 65^{\circ} \mathrm{C}$ and $66^{\circ} \mathrm{C}$ ), reaction time (8 time points, with $15 \mathrm{~min}, 30 \mathrm{~min}$, $45 \mathrm{~min}, 60 \mathrm{~min}, 75 \mathrm{~min}$ and $90 \mathrm{~min}$ ), sensitivity (namely detection limit) and specificity of both the primers and integron types. LAMP assays were carried out in 3 different reaction mixture volumes, containing $1.6 \mu \mathrm{M}$ (each) of the primers FIP and BIP, $0.2 \mu \mathrm{M}$ (each) of the primers F3 and B3, $0.8 \mu \mathrm{M}$ (each) of primers LF and LB (for each

Table 2 List of oligonucleotide primers used in this study

\begin{tabular}{|c|c|c|c|c|}
\hline Target & Sequence $\left(5^{\prime}\right.$ to $\left.3^{\prime}\right)$ & Size (bp) & Position & GenBank no. \\
\hline intl1 & & & & AF550415 \\
\hline F3 & AACAGTCTTGTACAAGTCCA & 20 & $903-922$ & \\
\hline B3 & GGTGCTITTGATATTITCCG & 21 & 1075-1095 & \\
\hline FIP & СTCTCTITCCTCTGCGGTCCTITTGATGTITTCACACTTATTGGAT & 43 & 936-958, 976-995 & \\
\hline BIP & TAAGGAATCACCTTGCAGATAAACTIIITAGTACATTGGCATCGTGT & 43 & $1000-1024,1057-1074$ & \\
\hline LF & CCAGAGTTAAGATTGAT & 17 & $959-975$ & \\
\hline LB & CGAAACAAGGCCAGTTITTTACC & 23 & $1028-1050$ & \\
\hline int 12 & & & & AP002527 \\
\hline F3 & TGTTGGAAGAATTTCTITTGA & 22 & $726-747$ & \\
\hline B3 & GCTAATAGCCCTGCGTATC & 19 & $924-942$ & \\
\hline FIP & CGCGATGCATGATGATGACAATTITIAGTGTTAATGCAATTCTGGGT & 43 & 748-768, 788-809 & \\
\hline $\mathrm{BIP}$ & GAGCTTCCTTCTATGTGCCCGTTTCAGAGTGGATGAGTCCCA & 39 & $832-852,895-912$ & \\
\hline LF & TCGCACCGTAATTATGACT & 19 & 769-787 & \\
\hline LB & AGATGGAAGAGTGCGTGGG & 19 & $855-873$ & \\
\hline int $/ 3$ & & & & AY219651 \\
\hline F3 & TCGGTGTCTGTTATTAACCA & 20 & 175-194 & \\
\hline B3 & TGGAAACCGTTGTCACAC & 18 & $371-388$ & \\
\hline FIP & AGACGAAGATGGTCAAAACGCTTTGCAGTTATTTGCTGTGGA & 40 & $206-224,252-272$ & \\
\hline BIP & CCGGGTTCGTTAATACGGCATTITCGGGCACTGATATATGTGT & 39 & $302-321,352-370$ & \\
\hline LF & TGATAGACATCAAGCCCTCGT & 21 & $228-248$ & \\
\hline LB & CAAATACTTTCTACCGTTT & 20 & $323-342$ & \\
\hline
\end{tabular}


individual primer), $6 \mathrm{mM} \mathrm{MgSO} 4,1.6 \mathrm{mM}$ of deoxynucleoside triphosphates, $1 \times$ thermopol buffer (New England Biolabs, Ipswich, MA, USA), 1 M betain (Sigma, St. Louis, MO, USA) and different amounts of template DNA. For LAMP reaction, initiation was started by heating at $95^{\circ} \mathrm{C}$ for $3 \mathrm{~min}$, followed by chilling on ice for $30 \mathrm{~s}$ with $1 \mu \mathrm{L}$ $(8 \mathrm{U})$ of Bst DNA polymerase (New England Biolabs, Ipswich, MA, USA) further added. After incubation at various temperatures ranging from $59^{\circ} \mathrm{C}$ to $66^{\circ} \mathrm{C}$ for $15 \mathrm{~min}-90 \mathrm{~min}$, the reaction was terminated by heating at $80^{\circ} \mathrm{C}$ for $2 \mathrm{~min}$. Simultaneously, PCR reactions were performed in parallel using the two outer primers F3 and B3, with the thermal profile as follows: $94^{\circ} \mathrm{C}$ for $5 \mathrm{~min}, 30$ cycles of $94^{\circ} \mathrm{C}$ for $30 \mathrm{~s}, 50^{\circ} \mathrm{C}$ for $30 \mathrm{~s}$, and $72^{\circ} \mathrm{C}$ for $30 \mathrm{~s}$ and a final extension cycle at $72^{\circ} \mathrm{C}$ for $7 \mathrm{~min}$. The primers used in this study are listed in Table 2 . The amplified products $(5 \mu \mathrm{L} /$ well $)$ were analyzed by gel electrophoresis in $2 \%$ agarose gels and stained with ethidium bromide for $10 \mathrm{~min}$. The detection limits of LAMP and PCR assays were ascertained by the determination of both minimal colony-forming units (CFU) and minimal template DNA amount of bacteria. In brief, overnight cultures and template DNAs from V. cholerae O1 strain SK-10, E. coli strain WF108314 and S. marcescens AK9373 were serially diluted 10 -fold with sterile water, ranging from $10^{2}$ to $10^{8} \mathrm{CFU} / \mathrm{mL}$ and $10^{-14}$ to $10^{-7} \mathrm{~g}$ DNA, respectively. A negative control was performed using sterile water instead of the bacterial culture or DNA.

\section{Application of LAMP assays on a large scale of bacterial isolates}

One thousand and eighty-two isolates were subjected to detection by the integron-screening LAMP and standard PCR assays as aforementioned (Table 1). Optimal parameter was used with LAMP reaction processed at $65^{\circ} \mathrm{C}$ for $45 \mathrm{~min}$. Heating and isothermal amplification were separately performed on the heating block and water bath. Positive LAMP reactions were measured by several qualitative criteria as follows: 1 . Observation of white magnesium pyrophosphate precipitates at the bottom of microfuge tubes, which were generated during the strand displacement autocycling reaction; 2 . Determination by staining with a $1 / 10$ dilution of SYBR Green I and visualization of a positive reaction both colorimetrically by the naked eye as well as imaging under an ultraviolet (UV) light source [51]. In addition, LAMP and PCR amplicons were also evaluated by electrophoresis as mentioned above. These experiments were performed in triplicates to ensure reproducibility.

\section{Competing interests}

The authors declare that they have no competing interests.

\section{Authors' contributions}

GY carried out the LAMP detection assays and drafted the manuscript. LC and $\mathrm{HC}$ carried out the DNA preparation and participated in the bacterial processing. $\mathrm{CL}$ and BL performed the statistical analysis. SC and JM carried out the sample collection and bacterial processing. HB participated in the design of the study and revised the manuscript. YD conceived of the study and participated in its design and coordination. DC participate in the design of the study and manuscript revision. All authors read and approved the final manuscript.

\section{Acknowledgements}

This work was supported by the National 973-Plan of China (2012CB720800), International Science \& Technology Cooperation Program from Science and Technology Planning Project of Guangdong Province, China (Dr. Bing Li, 2013-2016), National Natural Science Foundation of China (31201362 \& 31101278), the National Science and Technology Support Program (2012BAD37B01), National Outstanding Doctoral Dissertation Funding (Dr. Xu, 2014), Guangdong Outstanding Doctoral Dissertation Funding (K3140030), China Postdoctoral Science Foundation funded project (2014T70810 and 2013M542182), the Fundamental Research Funds for the Central Universities (2012ZM0060 and 2013ZB0021) and the Fund for Outstanding Youth of Anhui Academy of Agricultural Sciences (13B1212).

\section{Author details}

${ }^{1}$ First Affiliated Hospital of Jinan University, Guangzhou 510620, China. ${ }^{2}$ College of Light Industry and Food Sciences, South China University of Technology, 381 Wushan Road, Guangzhou 510640, China. ${ }^{3}$ Institute of Agro-products Processing, Anhui Academy of Agricultural Sciences, Hefei 230031, China. ${ }^{4}$ Institute of Biomedical Engineering, National Taiwan University, Taipei 10617, Taiwan. ${ }^{5}$ The Third Affiliated Hospital of Sun Yat-sen University, Guangzhou 510630, China. ${ }^{6}$ Department of Laboratory Medicine, First Affiliated Hospital of Guangzhou Medical College, 600 Tianhe Road, Guangzhou 510120, China.

Received: 27 May 2014 Accepted: 26 September 2014 Published: 2 October 2014

\section{References}

1. Xu Z, Li L, Shirtliff M, Peters B, Li B, Peng Y, Alam M, Yamasaki S, Shi L: Resistance class 1 integron in clinical methicillin-resistant Staphylococcus aureus strains in Southern China, 2001-2006. Clin Microbiol Infect 2011a, 17:714-717.

2. Xu Z, Li L, Zhao X, Chu J, Li B, Shi L, Su J, Shirtliff M: Development and application of a novel multiplex polymerase chain reaction (PCR) assay for rapid detection of various types of staphylococci strains. Afr J Microbiol Res 2011b, 5:1869-1873.

3. Zhong N, Gui Z, Xu L, Huang J, Hu K, Gao Y, Zhang X, Xu Z, Su J, Li B: Solvent-free enzymatic synthesis of 1,3-Diacylglycerols by direct esterification of glycerol with saturated fatty acids. Lip Heal Dis 2013, 12:65-72.

4. Xu Z, Li L, Shi L, Shirtliff M: Class 1 integron in staphylococci. Mol Biol Rep 2011a, 38:5261-5279.

5. Stokes HW, Hall RM: A novel family of potentially mobile DNA elements encoding site-specific gene-integration functions: integrons. Mol Microbiol 1989, 3:1669-1683.

6. Hall RM, Stokes HW: Integrons: novel DNA elements which capture genes by site-specific recombination. Genetica 1993, 90:115-132.

7. Hall RM, Brown HJ, Brookes DE, Stokes HW: Integrons found in different locations have identical $5 \mathrm{~b}$ ends but variable $3 \mathrm{~b}$ ends. J Bacterio/ 1994, 176:6286-6294.

8. Hall RM, Collis CM: Mobile gene cassettes and integrons: capture and spread of genes by site-specific recombination. Mol Microbiol 1995, 15:593-600

9. Collis CM, Grammaticopoulos G, Briton J, Stokes HW, Hall RM: Site-specific insertion of gene cassettes into integrons. Mol Microbiol 1993, 9:41-52.

10. Collis CM, Hall RM: Expression of antibiotic resistance genes in the integrated cassettes of integrons. Antimicrob Agents Chemother 1995, 39:155-162

11. Collis CM, Kim MJ, Stokes HW, Hall RM: Binding of the purified integron DNA integrase Int/1 to integron- and cassette-associated recombination sites. Mol Microbiol 1995, 29:477-490.

12. Hall RM, Collis CM: Antibiotic resistance in gram-negative bacteria: the role of gene cassettes and integrons. Drug Res Updates 1998, 1:109-119. 
13. Hall RM, Collis CM, Kim MJ, Partridge SR, Recchia GD, Stokes HW: Mobile gene cassettes and integrons in evolution. Ann N Y Acad Sci 1999, 870:68-80.

14. Stokes HW, O'Gorman DB, Recchia GD, Parsekhian M, Hall RM: Structure and function of 59-base element recombination sites associated with mobile gene cassettes. Mol Microbiol 1997, 26:731-745.

15. Boucher $Y$, Labbate M, Koenig JE, Stokes HW: Integrons: mobilizable platforms that promote genetic diversity in bacteria. Trends Microbiol 2007, 15:301-309.

16. Fluit AC, Schmitz FJ: Class 1 integrons, gene cassettes, mobility, and epidemiology. Eur J Clin Microbiol Infect Dis 1999, 18:761-770.

17. Fluit AC, Schmitz FJ: Resistance integrons and super-integrons. Clin Microbiol Infect 2004, 10:272-288.

18. Mazel D: Integrons: agents of bacterial evolution. Nat Rev Microbiol 2006, 4:608-620.

19. Labbate M, Case RJ, Stokes HW: The Integron/Gene Cassette System: An Active Player in Bacterial Adaptation. Horizontal Gene Transfer, Genomes in Flux, Springer 532, Chapter 6; 2009.

20. Francia MV, Zabala JC, de la Cruz F, Garcia Lobo JM: The Int/1 integron integrase preferentially binds single stranded DNA of the attC site. J Bacteriol 1999, 181:6844-6849.

21. Segal H, Francia MV, Lobo JM, Elisha G: Reconstruction of an active integron recombination site after integration of a gene cassette at a secondary site. Antimicrob Agents Chemother 1999, 43:2538-2541.

22. Mazel D, Dychinco B, Webb VA, Davies J: Antibiotic resistance in the ECOR collection: integrons and identification of a novel aad gene. Antimicrob Agents Chemother 2000, 44:1568-1574.

23. Recchia GD, Hall RM: Gene cassettes, a new class of mobile element. Microbiol 1995, 141:3015-3027.

24. Xu Z, Li L, Shirtliff M, Alam M, Yamasaki S, Shi L: Occurrence and characteristics of class 1 and 2 integrons in Pseudomonas aeruginosa isolates from patients in Southern China. J Clin Microbiol 2009, 47:230-234.

25. Rowe-Magnus DA, Mazel D: Integrons: natural tools for bacterial genome evolution. Curr Opin Microbiol 2001, 4:565-569.

26. Wang L, Li Y, Xu Z, Zhong Q: Development and application of a simple loop-mediated isothermal amplification method on rapid detection of Listeria monocytogenes strains. Mol Biol Rep 2012, 39:445-449.

27. Notomi T, Okayama H, Masubuchi H, Yonekawa T, Watanabe K, Amino N, Hase T: Loop-mediated isothermal amplification of DNA. Nucleic Acids Res 2000, 28:e63.

28. Mori Y, Nagamine K, Tomita N: Detection of loop-mediated isothermal amplification reaction by turbidity derived from magnesium pyrophosphate formation. Biochem Bioph Res Co 2001, 289:150-154.

29. Nagamine K, Watanabe K, Ohtsuka K: Loop-mediated isothermal amplification reaction using a nondenatured template. Clin Chem 2001, 47:1742-1743.

30. Zhao X, Li Y, Wang L, You L, Xu Z, Li L, He X, Liu Y, Wang J, Yang L: Development and application of a loop-mediated isothermal amplification method on rapid detection Escherichia coli 0157 strains from food samples. Mol Biol Rep 2010a, 37:2183-2188.

31. Zhao X, Wang L, Chu J, Li Y, Li Y, Xu Z, Li L, Shirtliff M, He X, Liu Y, Wang J, Yang $L$ : Development and application of a rapid and simple loop-mediated isothermal amplification method for food-borne Salmonella detection. Food Sci Biotechnol 2010b, 19:1655-1659.

32. Zhao X, Wang L, Chu J, Li Y, Li Y, Xu Z, Li L, Shirtliff M, He X, Liu Y, Wang J, Yang L: Rapid detection of Vibrio parahaemolyticus strains and virulent factors by loop-mediated isothermal amplification assays. Food Sci Biotechnol 2010c, 19:1191-1197.

33. Zhao X, Wang L, Li Y, Xu Z, Li L, He X, Liu Y, Wang J, Yang L: Development and application of a loop-mediated isothermal amplification method on rapid detection of Pseudomonas aeruginosa strains. World J Microbiol Biotechnol 2011, 27:181-184.

34. Horisaka T, Fujita K, Iwata T, Nakadai A, Okatani AT, Horikita T, Taniguchi T, Honda $\mathrm{E}$, Yokomizo $\mathrm{Y}$, Hayashidani $\mathrm{H}$ : Sensitive and specific detection of Yersinia pseudotuberculosis by loop-mediated isothermal amplification. J Clin Microbiol 2004, 42:5349-5352.

35. Ohtsuka M, Yanagawa K, Takatori K: Detection of Salmonella enterica in naturally contaminated liquid eggs by loop-mediated isothermal amplification, and characterization of Salmonella isolates. Appl Environ Microbiol 2005, 71:6730-6735.
36. Okamura M, Ohba Y, Kikuchi S, Suzuki A, Tachizaki H, Takehara K, Ikedo M, Kojima T, Nakamura M: Loop-mediated isothermal amplification for the rapid, sensitive, and specific detection of the 09 group of Salmonella in chickens. Vet Microbiol 2008, 132:197-204.

37. Ueda S, Kuwabara Y: The rapid detection of Salmonella from food samples by Loop-mediated isothermal amplification (LAMP). Biocontrol Sci 2009, 14:73-76.

38. Chen S, Ge B: Development of a toxR-based loop-mediated isothermal amplification assay for detecting Vibrio parahaemolyticus. BMC Microbiol 2010, 10:41-45

39. Nemoto J, Sugawara C, Akahane K, Hashimoto K, Kojima T, Ikedo M, Konuma H, Hara-Kudo Y: Rapid and specific detection of the thermostable direct hemolysin gene in Vibrio parahaemolyticus by loop-mediated isothermal amplification. J Food Prot 2009, 72:748-754.

40. Yamazaki W, Ishibashi M, Kawahara R, Inoue K: Development of a loop-mediated isothermal amplification assay for sensitive and rapid detection of Vibrio parahaemolyticus. BMC Microbiol 2008, 8:163-167.

41. Yamazaki W, Kumeda Y, Misawa N, Nakaguchi Y, Nishibuchi M: Development of a loop-mediated isothermal amplification assay for sensitive and rapid detection of the $t d h$ and trh genes of Vibrio parahaemolyticus and related Vibrio species. Appl Environ Microbiol 2010, 76:820-828.

42. Wang L, Zhao X, Chu J, Li Y, Li Y, Li C, Xu Z, Zhong Q: Application of an improved loop-mediated isothermal amplification detection of Vibrio parahaemolyticus from various seafood samples. Afr J Microbiol Res 2011, 5:5765-5771.

43. Xu Z, Li L, Chu J, Peters B, Harris M, Li B, Shi B, Shirtliff M: Development and application of loop-mediated isothermal amplification assays on rapid detection of various types of staphylococci strains. Food Res Int 2012a, 47:166-173.

44. Parida M, Horioke $\mathrm{K}$, Ishida $\mathrm{H}$ : Rapid detection and differentiation of dengue virus serotypes by a real-time reverse transcription-loop-mediated isothermal amplification assay. J Clin Microbiol 2005, 43:2895-2903.

45. Kaneko H, Kawana T, Fukushima E, Suzutani T: Tolerance of loop-mediated isothermal amplification to a culture medium and biological substances. J Biochem Bioph Meth 2007, 70:499-501.

46. You R, Gui Z, Xu Z, Shirtliff M, Yu G, Zhao X, Shi L, Li B, Su J, Li L: Methicillin-Resistance Staphylococcus aureus Detection by an improved rapid PCR assay. Afr J Microbiol Res 2012, 6:7131-7133.

47. Xu Z, Shi L, Zhang C, Zhang L, Li X, Cao Y, Li L, Yamasaki S: Nosocomial infection caused by class 1 integron-carrying Staphylococcus aureus in a hospital in South China. Clin Microbiol Infect 2007, 13:980-984.

48. Xu Z, Shi L, Alam M, Li L, Yamasaki S: Integron-bearing methicillin-resistant coagulase-negative staphylococci in South China, 2001-2004. FEMS Microbiol Lett 2008a, 278:223-230.

49. Xu Z, Li L, Alam M, Yamasaki S, Shi L: First confirmation of integron-bearing methicillin-resistant Staphylococcus aureus. Curr Microbiol 2008, 57:264-268.

50. Xu Z, Li L, Shirtliff M, Peters B, Peng Y, Alam M, Yamasaki S, Shi L: First report of class 2 integron in clinical Enterococcus faecalis and class 1 integron in Enterococcus faecium in South China. Diag Microbiol Infect Dis 2010, 68:315-317.

51. Xu Z, Gui Z, Zhao X, Zhang Y, He X, Li W, Yang L: Expression and purification of gp41-gp36 fusion protein and application in serological screening assay of HIV-1 and HIV-2. Afr J Microbiol Res 2012b, 6:6295-6299.

52. Deng Y, Liu J, Peters BM, Chen L, Miao J, Li B, Li L, Chen D, Yu G, Xu Z, Shirtliff ME: Antimicrobial resistance investigation on Staphylococcus strains in a local hospital in Guangzhou, China, 2001-2010. Microb Drug Resist 2014, DOI: 10.1089/mdr.2014.0117.

doi:10.1186/0717-6287-47-53

Cite this article as: Yu et al.: Loop-mediated isothermal amplification assays for screening of bacterial integrons. Biological Research 2014 47:53. 